\title{
Quality of life of women with breast cancer undergoing chemotherapy
}

\author{
Qualidade de vida de mulheres com câncer mamário submetidas à quimioterapia
}

Edianne Sílvia Lustosa Cesar ${ }^{1}$, Inez Sampaio Nery ${ }^{1}$, Államy Danilo Moura e Silva ${ }^{1}$, Juliana Teixeira Nunes ${ }^{1}$, Ana Fátima Carvalho Fernandes ${ }^{2}$

Objective: to analyze the quality of life of women with breast cancer undergoing chemotherapy. Methods: a cross-sectional study with 76 women. We used the European Organization for Research and Treatment of Cancer Core Quality of Life Questionnaire-30 and Supplementary Questionnaire Breast Cancer Module. Results: there was a low correlation between socio-demographic and clinical variables with the quality of life domains. The best scores corresponded to women from 49 to 51 years old, married, dark-skinned, better schooling and formal work. The least mentioned symptoms were: Swollen breast (84.2\%), Vomiting (81.6\%); Shortness of breath (80.3\%). Conclusion: general health presented satisfactory average, which suggests a good quality of life according to the European Organization for Research and Treatment of Cancer Core Quality of Life Questionnaire-30. However, the Functional and Symptoms domains, as measured by Supplementary Questionnaire Breast Cancer Module, were negatively influenced by old age and larger cycles of chemotherapy.

Descriptors: Breast Neoplasms; Quality of Life; Drug Therapy; Nursing Care.

Objetivo: analisar a qualidade de vida de mulheres com câncer mamário submetidas à quimioterapia. Métodos: estudo transversal com 76 mulheres. Foram utilizados os European Organization for Research and Treatment of Cancer Core Quality of Life Questionnaire-30 e Supplementary Questionnaire Breast Cancer Module. Resultados: houve fraca correlação entre variáveis sociodemográficas e clínicas com domínios de Qualidade de Vida. Os melhores escores foram mulheres de 49 a 51 anos, casadas, pardas, melhor escolaridade e trabalho formal. Os sintomas menos referidos foram: Inchaço no seio doente (84,2\%), Vômitos (81,6\%); Falta de ar (80,3\%). Conclusão: a saúde geral apresentou média considerada satisfatória, o que sugere boa qualidade de vida no European Organization for Research and Treatment of Cancer Core Quality of Life Questionnaire-30. Entretanto, os domínios Funcional e de Sintomas, medidos pelo questionário Supplementary Questionnaire Breast Cancer Module, foram negativamente influenciados pela idade avançada e maiores ciclos de quimioterapia.

Descritores: Neoplasias da Mama; Qualidade de Vida; Tratamento Farmacológico; Cuidados de Enfermagem.

\footnotetext{
${ }^{1}$ Universidade Federal do Piauí. Teresina, PI, Braszil.

${ }^{2}$ Universidade Federal do Ceará. Fortaleza, CE, Brazil. 


\section{Introduction}

Breast cancer is considered a disease with major impact on public health, being the first cause of death from cancer, with increasing mortality rates and incidence in female population ${ }^{(1)}$. In Brazil, the National Cancer Institute estimates, for the year 2017, about 57,960 of new breast cancer cases in women, numbers that correspond to the gross rate of incidence of 56.2 cases for every 100,000 inhabitants $^{(2)}$.

When diagnosed and treated in the early stages, breast cancer has a good prognosis ${ }^{(3)}$. In general, the treatment of mammary neoplasms requires a combination of several methods such as surgical and radiation therapy, described as located therapeutic forms; and systemic arrangements like pharmacological treatments and biological therapy, which increase the possibility of cure, decrease anatomic losses, preserve the aesthetics and function of the organs committed ${ }^{(4)}$.

Pharmacological treatment with chemotherapy is one of the main modes for cure, control, and minimization of the condition. However, it generates harmful effects, ranging from quality and intensity, makes difficult to accept it and threatens the patients' welfare $^{(5)}$. Among the side effects of this modality, immunosuppression, nausea, vomiting, alopecia, renal toxicity, cardiovascular, pulmonary, neurological and water-electrolyte imbalance are mainly responsible for increasing the patients' weakness ${ }^{(6)}$.

In addition to the physical effects, we have to emphasize the influence of chemotherapy treatment on the psychological state of the woman since it affects their self-esteem, sexuality, body image, mood, family relationships and social skills ${ }^{(7)}$. Thus, the patient experiences physical, psycho-emotional, spiritual, social and economic discomforts, that interfere directly in the quality of life. So, analyzing the quality of life of a person, by these parameters, means looking for qualifying their well-being ${ }^{(8)}$.

In this perspective, before the epidemiological characteristics that suggest the impacts of mammary neoplasia in women, we realized there is a vast inte- rest in monitoring the quality of life of the patients in chemotherapy, seeking to measure the side effects induced by the treatment and developing therapies that stimulate a better adaptation to the disease, cancer treatment and nursing care $^{(9)}$.

When considering the effects produced by chemotherapy in the overall well-being of women with breast cancer, as well as factors that contribute to the increase waiver and abandonment of the treatment, the quality of life of these women emerged as an object of research, from the following question: how is the quality of life of women with breast cancer during treatment with chemotherapy?

The study aimed to analyze the quality of life of women with breast cancer undergoing chemotherapy.

\section{Methods}

A cross-sectional study, conducted from October to December 2015, in the Chemotherapy area of a philanthropic hospital that is reference in oncological treatment in the State of Piauí, Northeast region of Brazil, which serves people from the public health system and private insurance.

We used the probabilistic method of unintentional selection for convenience as sampling criterion. Women who had medical diagnosis of mammary neoplasia and undergoing outpatient treatment with anticancer medication, were included. The exclusion criterion was the diagnosis of degenerative, neurological and/or phonetics conditions that prevents a consistent dialogue. A sample of 76 women was obtained.

The data collection was carried out during nine weeks through a semi-structured interview with close-ended questions and secondary data. The form used was divided in two parts. The first consisted of socio-demographic and clinical data: age group; marital status; color; schooling; religion; type of work; family income; time of diagnosis; number of cycles and previous treatment.

The second part was formed by the following instruments: European Organization for Research 
and Treatment of Cancer Core Quality of Life Questionnaire - 30 (EORTC QLQ-C30), multidimensional and self-administered, which evaluates the quality of life in patients with cancer in 30 questions about the symptoms that occurred in the last two weeks divided in global health, functional and symptoms domains; and the Supplementary Questionnaire Breast Cancer Module, specific to evaluate patients with breast cancer treated or on treatment, with 23 issues that complement the general questionnaire and is divided into the functional and symptoms domains. International instruments were duly validated for the Brazilian population in a study of 100 women with breast cancer between 27 and 90 years old ${ }^{(10)}$.

Next, we analyzed the frequency and intensity of the symptoms as side effects related to treatment with chemotherapy. The database was analyzed in the program Software Statistical Package for Social Science version 20.0 for definitive management operations, such as: creating new variables; final categorization of variables in range; and analysis of data. The quality of life form was evaluated by the Kolmogorov-Smirnov test to verify the adherence of the domains to normal distribution. As data followed a normality trend, parametric tests were used.

For each domain, the Cronbach's alpha was verified, in order to identify the suitability of it to the reality studied. In the descriptive analysis, the average scores and the standard deviation were calculated, and the Variance Analysis parametric test compared the domains of the instruments used with socio-demographic and clinical data. All scores averages were transformed into a scale of zero to 100 points, according to the manual of the European Organization for Research and Treatment of Cancer, in which zero represents the worst quality of life and 100 , the best state of health except for symptom scales, in which the higher score represents more symptoms. The analysis by the Student's $t$ test for independent samples was performed to evaluate the quantitative and categorical variables, and verify whether the results obtained were statistically significant $(\mathrm{p} \leq 0.05)$.

The study complied with the formal requirements contained in the national and international regulatory standards for research involving human beings.

\section{Results}

The association of socio-demographic and clinical variables to domains of quality of life of the instruments applied, showed low correlation. Table 1 shows the sociodemographic variables in the Global Health domain in which better quality of life scores corresponded to women from 41 to 59 years old (78.0), married (78.0), black (90.4), high school (86.4), not Catholic (79.0), formal job (79.0) and family income from two to four minimum wages (83.3).

The best socio-demographic scores to the Functional domain were presented by participants from 60 to 80 years old (75.2), married or in a stable relationship (69.5), yellow skinned (80.4), illiterate (75.5), Catholic (68.4), with formal job (70.8) and family income from two to four minimum wages (76.3). The Symptoms domain obtained better averages among women from 60 to 80 years old (23.4), married or in a stable relationship (28.0), yellow skinned (19.2), illiterate (29.3), Catholic (29.4), with formal job (27.1) and family income from two to four minimum wages (25.1) (Table 1).

In clinical variables, women diagnosed less than 1 year ago (77.9) and between 2 and 4 years ago (78.9) presented the best Global Health domain scores for the variable time of diagnosis. As for the number of chemotherapy cycles, the participants with less than 1 to 4 cycles (84.5) had the most positive results. Other categories were 5 to 8 (71.4) and from 9 to 18 (74.0) cycles. Analyzing the issue about having undergone a treatment for breast cancer before, 52 women said yes and 24 answered no, and the best scores were for those who did not undergo a previous treatment (80.1). 
Table 1 - Association of socio-demographic variables to domains of quality of life according to the instrument European Organization for Research and Treatment of Cancer Core Quality of Life Questionnaire - 30

\begin{tabular}{lcccc}
\hline \multirow{2}{*}{ Variable } & & \multicolumn{2}{c}{$\begin{array}{c}\text { Global } \\
\text { Health } \\
\text { Domain }\end{array}$} & \multicolumn{2}{c}{$\begin{array}{c}\text { Functional } \\
\text { Domain }\end{array}$} & $\begin{array}{c}\text { Symptoms } \\
\text { Domain }\end{array}$ \\
\cline { 2 - 5 } & & Average (SD) & $\begin{array}{c}\text { Average } \\
\text { (SD) }\end{array}$ & $\begin{array}{c}\text { Average } \\
\text { (SD) }\end{array}$ \\
\hline $\begin{array}{l}\text { Age group (years old)* } \\
20-40\end{array}$ & 10 & $73.3(17.0)$ & $61.1(24.0)$ & $32.3(20.2)$ \\
$41-59$ & 48 & $78.0(23.3)$ & $66.3(21.4)$ & $31.7(20.0)$ \\
$60-80$ & 18 & $75.5(26.1)$ & $75.2(13.1)$ & $23.4(14.0)$ \\
p-value & & 0.821 & 0.160 & 0.255
\end{tabular}

\section{Marital status*}

Single

Married

Divorced

Widowed

p-value

Color*

White

Black

Dark

Yellow

P value

Schooling*

Illiterate

Elementary school

High school

University

p-value

Religion**

Catholic

Not Catholic

p-value

Work*

$\begin{array}{lcccc}\text { Formal job } & 25 & 79.0(20.6) & 70.8(18.4) & 27.1(16.4) \\ \text { Informal job } & 19 & 73.7(21.9) & 64.6(19.3) & 33.5(16.8) \\ \text { Housewife } & 32 & 76.8(26.0) & 67.3(22.7) & 29.7(21.8) \\ \text { p-value } & & 0.757 & 0.605 & 0.543\end{array}$

Family income*

(Minimum wage ${ }^{* * *}$ )

$$
<2
$$

$2-4$

4-10

$10 \quad 72.5(31.9) \quad 62.0(22.3) 29.7(20.2)$

$45 \quad 78.0(19.9) \quad 69.5(19.0) \quad 28.0(17.5)$

$\begin{array}{llll}10 & 76.7(21.4) & 64.7(23.2) & 29.7(20.9)\end{array}$

$11 \quad 75.8(30.2) \quad 68.5(23.5) \quad 37.1$ (22.2)

$\begin{array}{lll}0.926 & 0.716 & 0.577\end{array}$

$17 \quad 70.6(30.4) \quad 65.9(24.3) \quad 32.0(24.5)$

$13 \quad 90.4(13.6) \quad 73.7(11.5) 25.8(11.2)$

$\begin{array}{llll}40 & 74.2(22.1) & 64.7(21.7) & 31.7(18.8)\end{array}$

$\begin{array}{llll}6 & 81.9(11.1) & 80.4(4.0) & 19.2(12.4)\end{array}$

$\begin{array}{lll}0.085 & 0.222 & 0.382\end{array}$

$07 \quad 78.6(17.3) \quad 75.5(15.8) 29.3(15.0)$

$49 \quad 74.7(26.4) \quad 65.5(21.3) \quad 31.7(19.6)$

$11 \quad 86.4(15.9) \quad 68.9(17.5) \quad 27.7(18.6)$

$9 \quad 75.0(11.8) \quad 72.4(22.3) 22.2(18.5)$

$\begin{array}{lll}0.502 & 0.561 & 0.562\end{array}$

$\begin{array}{llll}55 & 75.9(23.5) & 68.4(20.4) & 29.4(18.9)\end{array}$

$2179.0(22.5) \quad 65.9(20.8) \quad 30.8(19.3)$

$0.608 \quad 0.635 \quad 0.783$

$6-66.6(27.4) \quad 71.1(21.8) 26.5(26.3)$

${ }^{*}$ ANOVA Test; ${ }^{* *}$ Student's t-test. ${ }^{* * *}$ Minimum wage (R\$ 788,00). SD: Standard Deviation
In the Functional domain, when measuring the life quality with the time of diagnosis, the best results were for the shorter diagnosis time (69.8) and the findings as to the time of diagnosis were between 2 and 4 years ago (67.2) and more than 4 years (61.4). The scores of the number of chemotherapy cycles were, from 1 to 4 (69.5), 5 to 8 (68.2) and 9 to 18 (63.8) cycles. Women who did not undergo previous treatment (72.5) obtained better result in this issue. The Symptoms domain presented better scores when the time of diagnosis was shorter (26.3) and in those who did not undergo previous treatment (25.5).

The association of socio-demographic variables to the domains of quality of life, according to the specific instrument for breast cancer, Supplementary Questionnaire Breast Cancer Module, also showed low correlation. The highest scores for the Functional domain were presented by women between 60 and 80 years old (49.9), single (55.6), yellow skinned (54.5), illiterate (53.7), Catholic (46.9), housewives (52.5) and with family income from two to four minimum wages (57.7). In the Symptoms domain, the participants from 60 to 80 years old (31.9), single women (28.9), dark (27.6), with higher education (26.4), not Catholic (32.9), with formal job (32.6) and family income from four to ten minimum wages (25.0), presented better scores for quality of life.

Table 2 shows the association of clinical variables to quality of life domains, according to the specific instrument Supplementary Questionnaire Breast Cancer Module. Analyzing the Functional domain, the best averages corresponded to women who received the diagnosis more than 4 years ago (51.7), with fewer cycles of chemotherapy (51.1) and who did not undergo a breast neoplasm treatment before (50.4).

In the Symptoms domain, the best scores corresponded to the shortest time of diagnosis (31.4), undergoing between the fifth and the eighth cycle of chemotherapy (31) and who have not received any other previous treatment for breast cancer (31.9) (Table 2). 
Table 2 - Association of clinical variables to domains of quality of life according to the instrument Supplementary Questionnaire Breast Cancer Module

\begin{tabular}{|c|c|c|c|}
\hline \multirow{2}{*}{ Variable } & \multirow[t]{2}{*}{$\mathbf{n}$} & $\begin{array}{c}\text { Functional } \\
\text { Domain }\end{array}$ & $\begin{array}{c}\text { Symptoms } \\
\text { Domain }\end{array}$ \\
\hline & & Average (SD) & Average (SD) \\
\hline \multicolumn{4}{|c|}{ Time of diagnosis (years)* } \\
\hline$\leq 1$ & 46 & $47.5(25.8)$ & $31.4(20.8)$ \\
\hline $2-4$ & 17 & $45.9(21.4)$ & $38.1(20.1)$ \\
\hline$\geq 4$ & 13 & $51.7(20.8)$ & $34.8(16.8)$ \\
\hline $\mathrm{p}$ value & & 0.800 & 0.487 \\
\hline \multicolumn{4}{|c|}{ Number of cycles* } \\
\hline $1-4$ & 28 & $51.1(24.1)$ & $34.4(19.5)$ \\
\hline $5-8$ & 32 & $45.9(22.5)$ & $31.0(19.6)$ \\
\hline $9-18$ & 16 & $46.1(27.0)$ & $36.8(22.1)$ \\
\hline $\mathrm{p}$ value & & 0.663 & 0.614 \\
\hline \multicolumn{4}{|c|}{ Previous tratment** } \\
\hline Yes & 52 & $46.7(22.7)$ & $34.2(20.7)$ \\
\hline No & 24 & $50.4(26.6)$ & $31.9(18.5)$ \\
\hline $\mathrm{p}$ value & & 0.533 & 0.646 \\
\hline
\end{tabular}

The clinical profile of the participants showed that more than half of the sample obtained the diagnosis of breast cancer less than a year ago and used predominantly paclitaxel and Trastuzumab, they were between the fifth and the eighth cycle of chemotherapy and underwent surgery as previous treatment.

Table 3 shows the frequency and intensity of the treatment side effects. We can infer that the absence of symptoms is one of the parameters to the best quality of life, and the complaints less mentioned by women during chemotherapy cycles were: Swelling in the sick breast area (84.2\%), Vomiting (81.6\%); Shortness of breath $(80.3 \%)$ and diarrhea $(78.9 \%)$.

The descriptive analysis and internal consistency of the EORTC QLQ-C30 instrument showed that the Functional domain presented the best connection (0.90), followed by the Symptoms (0.87). All the scores have a good quality of life average since in Global and Functional health, the higher the score, the better the quality of life. In the Symptoms domain, the higher the score, the greater the amount of symptoms and, consequently, a worse quality of life. In the specific form Supplementary Questionnaire Breast Cancer Module, the average score of the Functional domain was 47.9 , which represents a low average of quality of life, and the Symptoms was 33.5.

Table 3 - Frequency and intensity distribution of treatment-related side effects in the sample under study

\begin{tabular}{|c|c|c|c|c|c|}
\hline \multirow[t]{2}{*}{ Simptoms } & No & Low & Moderate & High & $\begin{array}{c}\text { Not } \\
\text { applied }\end{array}$ \\
\hline & $\%$ & $\%$ & $\%$ & $\%$ & $\%$ \\
\hline Shortness of breath & 80.3 & 14.5 & 3.9 & 1.3 & - \\
\hline Pain & 38.2 & 26.3 & 11.8 & 23.7 & - \\
\hline Need of rest & 34.2 & 22.4 & 19.7 & 23.7 & - \\
\hline Sleeping problems & 42.1 & 15.8 & 14.5 & 27.6 & - \\
\hline Weakness & 44.7 & 21.1 & 13.2 & 21.1 & - \\
\hline Lack of appetite & 51.3 & 25.0 & 6.6 & 17.1 & - \\
\hline Nausea & 48.7 & 25.0 & 5.3 & 21.1 & - \\
\hline Vomiting & 81.6 & 13.2 & 1.3 & 3.9 & - \\
\hline Constipation & 69.7 & 14.5 & 3.9 & 11.8 & - \\
\hline Diarrhea & 78.9 & 14.5 & 0.0 & 6.6 & - \\
\hline Fatigue & 56.6 & 27.6 & 9.2 & 6.6 & - \\
\hline Dry mouth & 32.9 & 22.4 & 11.8 & 32.9 & - \\
\hline Taste changes & 38.2 & 23.7 & 9.2 & 28.9 & - \\
\hline View symptoms & 52.6 & 18.4 & 7.9 & 21.1 & - \\
\hline Hair loss & 57.9 & 6.6 & 2.6 & 32.9 & - \\
\hline $\begin{array}{l}\text { When hair loss, uncomfort- } \\
\text { able level }\end{array}$ & 26.3 & 7.9 & 10.5 & 44.7 & 55.3 \\
\hline Feeling unwell & 42.1 & 22.4 & 19.7 & 15.8 & - \\
\hline Chills & 35.5 & 15.8 & 15.8 & 32.9 & - \\
\hline Headache & 59.2 & 14.5 & 9.2 & 17.1 & - \\
\hline Arm or shoulder pain & 43.4 & 19.7 & 13.2 & 23.7 & - \\
\hline Arm or shoulder swelling & 76.3 & 11.8 & 3.9 & 7.9 & - \\
\hline Moving the arm difficulty & 60.5 & 14.5 & 11.8 & 13.2 & - \\
\hline Sick breast area pain & 46.1 & 25.0 & 15.8 & 13.2 & - \\
\hline Sick breast area swelling & 84.2 & 2.6 & 3.9 & 9.2 & - \\
\hline Sick breast area sensitivity & 43.4 & 22.4 & 9.2 & 25.0 & - \\
\hline Skin problems & 44.7 & 14.5 & 10.5 & 30.3 & - \\
\hline
\end{tabular}




\section{Discussion}

The limitations are related to the small size of the sample and the implementation into a single Department of Oncology, which holds greater demand of patients in the State of Piauí in the Northeast region. Therefore, the results cannot be generalized. The guiding question can be addressed in further research, considering the cross design does not allow to establish cause and effect relationships.

It is considered that age is strongly related to the emotional function, and it is a factor that influences the quality of life, whose physical and sexual function scores decreased when age increased ${ }^{(11-12)}$. However, the study did not provide relevant correlation between age and the domains of quality of life and also showed an increase in scores of the Functional, as well as in the Global health and Symptoms domains, reaching better scores with an increasing age.

The time of diagnosis evidently influenced in the quality of life ${ }^{(13)}$. Among the women of this study, the diagnostic time showed that the sooner the discovery of the disease, the better were the scores of the Functional and Symptoms domains of the EORTC QLQ-C30, and opposite to the questionnaire findings.

With respect to a previous treatment for breast cancer, the study showed that the best scores for all domains of quality of life were achieved by the participants who did not undergo any type of previous treatment, as opposed to what the literature points, about the good evolution in certain ranges of Functional and Symptoms domains, as the appetite and constipation. However, a study highlights that scores related to body image, social function and diarrhea get worse with total breast surgery and radiotherapy, showing differences in the results of this correlation with quality of life ${ }^{(12)}$.

The participants that had less cycles of chemotherapy, between one and five, were those that showed better levels of quality of life in general, corroborating the results in the literature, which show that patients with more than six sessions of treatment obtained de- ficit in the emotional function and an increase in the range of symptoms ${ }^{(13)}$.

According to this study, adjuvant treatments affected the patients with breast cancer in the activities of daily living and on symptoms such as pain, swelling and vomiting, as observed in Functional and Symptoms domains scores. The toxicity of chemotherapy drugs taken, related to non-specificity cell, can generate effects such as pain, fatigue, vomiting, as well as anorexia, hindering the implementation of daily activities $^{(14)}$. A study found that adjuvant treatments are associated with a decrease in the quality of life in general, physical function, anxiety and body image and increase fatigue, dyspnea, pain, nausea and vomiting and constipation ${ }^{(15)}$.

Another research showed, in the Symptoms scales, that insomnia predominated, followed by pain, fatigue, loss of appetite, constipation, nausea and vomiting, dyspnea, while diarrhea was a less frequent symptom $^{(11)}$. In this study, intestinal symptom had low incidence, however, there were no predominantly symptoms mentioned in great intensity in the population.

As for the breast and arm symptoms, a study showed that in patients with Lymphedema, the intensity, quantity and time dedicated to the activities practiced decreases, as sun exposure and physical activities, due to social discomfort associated with the increased volume of the arm and breast, which interferes directly in the quality of life ${ }^{(16)}$. In this study, we observed good general conditions related to the symptoms related on arms and breast, despite was not found a meaningful relationship with the quality of life of the population studied.

Some studies show significant changes in various dimensions of quality of life of patients with breast cancer ${ }^{(12,15)}$. For example, a research showed that on the scales of the functional domains (physical, cognitive, social functions and role performance) the averages vary from 60.23 to 66.00 , indicating from regular to satisfactory level and in the emotional function, 
the average was 45.69 , which shows that the patients felt worried, depressed, angry and/or tense $\mathrm{e}^{(11)}$.

With respect to antineoplastic drugs, the patients who performed more than six sessions presented deficit in emotional function and increase in the Symptom score (indicating more symptoms present) to Dyspnea ${ }^{(11)}$. It is obvious that the adjuvant chemotherapy cause deficit in the Global Health domain ${ }^{(14)}$.

There is no consensus in the literature about the best health condition of patients with breast cancer during adjuvant treatment. It was found that the general quality of life, the functions performed and the presence of symptoms are different in each reality of the patients life ${ }^{(1,15,17)}$. Thus, it appears that the quality of life worsens during the treatment, however, other researches also showed that, over time, many patients can reestablish their activities and, with the maturity and support received, achieve progressive improvements of the symptoms and functions performed ${ }^{(11,17)}$.

We repeat that the results presented in this study should be interpreted with caution, due to the limitations found. However, having found that breast cancer patients in chemotherapy treatment showed losses in the areas of quality of life, it is necessary to investigate what measures may be taken to prevent damages arising from the treatment and improve the assistance and welfare of these women. Thus, more studies must be performed in order to use quality of life in clinic judgements as an indicator of the disease and their impact, and propose solutions to improve the affected domains and health care.

The results may contribute to health services in Oncology to raise awareness for the expansion of care to patients through the full assistance and not just by drug treatment. The health professional must be an expertise in this particular area, which requires study, humanization and autonomy, to work in the clinical follow-up, emotional support and holistic care of patients.

\section{Conclusion}

General health presented a satisfactory average, which suggests good quality of life according to the European Organization for Research and Treatment of Cancer Core Quality of Life Questionnaire-30. However, the Functional and Symptoms domains, as measured by Supplementary Questionnaire Breast Cancer Module, were negatively influenced by old age and larger cycles of chemotherapy.

\section{Collaborations}

Cesar ESL, Silva ADM and Nunes JT contributed in the project conception and design, analysis and interpretation of data, article and review of relevant intellectual content. Nery IS and Fernandes IS AFC contributed on the final approval of the version to be published.

\section{References}

1. Rodrigues JD, Cruz MS, Paixão AN. Uma análise da prevenção do câncer de mama no Brasil. Ciênc Saúde Coletiva. 2015; 20(10):316376.doi:http://dx.doi.org/10.1590/1413812320152010.20822014

2. Instituto Nacional de Câncer José Alencar Gomes da Silva. Coordenação Geral de Ações Estratégicas. Coordenação de Prevenção e Vigilância. Estimativa 2016: incidência de câncer no Brasil. Rio de Janeiro: Inca; 2015.

3. Moura JR, Baía Júnior WC. Fator prognóstico da idade no câncer de mama. Rev Bras Mastol. 2013; 23(3):81-6. doi: http://dx.doi.org/10.5327/ Z0104-8058201300030004

4. Bezerra KB, Silva DSM, Chein MBC, Ferreira PR, Maranhão JKP, Ribeiro NL, et al. Qualidade de vida de mulheres tratadas de câncer de mama em uma cidade do nordeste do Brasil. Ciênc Saúde Coletiva. 2013; 18(7):1933-41. doi: http://dx.doi. org/10.1590/S1413-81232013000700008. 
5. Schlosser TCM, Ceolim MF. Quality of life of cancer patients during the chemotherapy period. Texto ContextoEnferm.2012;21(3):600-7.doi:http://dx.doi.org/10.1590/S0104-07072012000300015

6. Courneya KS, Vallance JK, Culos-Reed SN, McNeely ML, Bell GJ, Mackey JR, et al. The Alberta moving beyond breast cancer (AMBER) cohort study: a prospective study of physical activity and healthrelated fitness in breast cancer survivors. BMC Cancer. 2012; 12(1):525. doi: http://dx.doi. org/10.1186/1471-2407-12-525

7. Zou Z, Hu J, McCoy TP. Quality of life among women with breast cancer living in Wuhan, China. Int J Nurs Sci. 2014; 1(1): 79-88. doi: http://dx.doi. org/10.1016/j.ijnss.2014.02.021

8. Almeida MAB. Qualidade de vida: definição, conceitos e interfaces com outras áreas, de pesquisa. São Paulo: Escola de Artes, Ciências e Humanidades - EACH/USP; 2012. Disponível em:http://each.uspnet.usp.br/edicoes-each/ qualidade_vida.pdf

9. Dallabrida AF, Loro MML, Rosanelli CLSP, Souza MM, Gomes JS, Kolankiewicz ACB. Quality of life of women undergoing treatment for cervical cancer. Rev Rene 2014; 15(1):116- 22. doi: http://dx.doi. org/10.15253/2175-6783.2014000100015

10. Michels FAS, Latorre MRDO, Maciel MS. Validity, reliability and understanding of the EORTC-C30 and EORTC-BR23, quality of life questionnaires specific for breast cancer. Rev Bras Epidemiol. 2013; 16(2):352-63. doi: http://dx.doi. org/10.1590/S1415-790X2013000200011

11. Kang KD, Bae S, Kim HJ, Hwang IG, Kim SM, Han $\mathrm{DH}$. The relationship between physical activity intensity and mental health status in patients with breast cancer. J Korean Med Sci. 2017; 32(8):1345-50. doi: http://dx.doi.org/10.3346/ jkms.2017.32.8.1345
12. Jassim GA, Whitford DL. Understanding the experiences and quality of life issues of Bahraini women with breast cancer. Soc Sci Med. 2014; 107: 189-95. doi: http://dx.doi.org/10.1016/j. socscimed.2014.01.031

13. Silva S, Crespo C, Canavarro MC. Pathways for psychological adjustment in breast cancer: a longitudinal study on coping strategies and posttraumatic growth. Psychol Health. 2012; 27(11):1323-41. doi: http://dx.doi.org/10.1080/ 08870446.2012 .676644

14. Lôbo SA, Fernandes AFC, de Almeida PC, Carvalho CML, Sawada NO. Quality of life in women with breast cancer undergoing chemotherapy. Acta Paul Enferm. 2014; 27(6):554-9. doi: http:// dx.doi.org/10.1590/1982-0194201400090

15. Gavric Z. Quality of life of women with breast cancer-emotional and social aspects. Am J Cancer Prev [Internet]. 2015 ]cited 2017 Sept 13]; 3(1):13-8. Available from: http://pubs.sciepub. com/ajcp/3/1/4/

16. Tuncay T. Coping and quality of life in Turkish women living with ovarian cancer. Asian Pac J Cancer Prev. 2014; 15(9):4005-12. doi: http:// dx.doi.org/10.7314/APJCP.2014.15.9.4005

17. Bagheri M, Mazaheri M. Body image and quality of life in female patients with breast cancer and healthy women. J Midwifery Reprod Health. 2015; 3(1):285-92. doi: http://dx.doi.org/10.22038/ JMRH.2015.3584 